\title{
ADHD WITH NON-ORGANIC ENURESIS AND BORDERLINE INTELLIGENT QUOTIENT
}

\author{
Frilya Rachma Putri ${ }^{1}$; Herman Yosef $^{2}$ \\ Correspondence:frilya.yudi@ub.ac.id \\ ${ }^{1}$ Child and Adolescent Psychiatry Department Medical Faculty Brawijaya University; ${ }^{2}$ General Practitioner Clinic IHC Bentoel Karanglo \\ Malang, Indonesia
}

\section{ABSTRACT}

Symptoms of Attention Deficit Hyperacitivity Disorder (ADHD) can be associated with nocturnal enuresis. Nocturnal enuresis cases are common occur in children with Mental Retardation. There are several hypotheses underlying this comorbidity, such as genetic, neurophysiological, environmental and psychosocial factors. We report the case of a 7 year old boy with symptoms such as inability to concentrate, active movement, talk a lot, unable to wait his turn, unable to delay desires, easy fighting and behaving and speaking harshly. Patients still wet the bed at night at least 3-4 times a week The Abbreviated Conners Score rating scale assessed by the mother at the start of treatment was 21. The IQ test score was 71 and the Strength and Difficulty Questionnaire (SDQ) score was 35. The patient's symptoms were reduced after 4-month therapy with $2 \times 5 \mathrm{mg}$ of methylphenidate administration, psychoeducation of parents to implement toilet training and behavior therapy for patients, apply reward and punishment with the principle of token economy. In the development process of children and adolescents, parenting is an important factor. Many studies shows that parenting can impact the resilience and vulnerability of a child to behavioral disorders. In children with ADHD with borderline IQ and enuresis, parenting with a high parental control component can cause psychological symptoms to worsen without being balanced with the attitude of parents who are responsive to the psychological needs of the child.

Keywords: ADHD, enuresis, psychoeducation, parenting.

\section{Article History:}

Received: November 28, 2020

Accepted: January 5, 2020

Published: March 24, 2020
Cite this as: Putri, FR. Yosef, H. Structural family therapy as mediation process for marital conflict. Journal of Psychiatry Psychology and Behavioral Research; 2021.1:1-3.

\section{INTRODUCTION}

Enuresis co-morbidities with mental disorders such as Attention Deficit Hyperactivity Disorder (ADHD) and Mental Retardation (RM) are quite common. From a study conducted by Yang and colleagues, $28.3 \%$ of 53 children aged 6-10 years who were diagnosed with ADHD had comorbid nocturnal enuresis. There are several hypotheses underlying this comorbidity, among others, from a genetic, neurophysiological, environmental and psychosocial perspective. $^{1}$

Genetic factors play an important role in the etiology of enuresis and ADHD, the heritability rate is quite high, which is around 0.7. Molecular genetic studies conducted by Elia and colleagues found that the genetic basis of these two disorders does not have the same gene base. ${ }^{1,2}$ In terms of functional deficits, it is hypothesized that the complex neuron network between the cortex, subcortex, and brainstem plays an important role in comorbidity between enuresis and cases of developmental delays. ${ }^{1}$
The tricyclic antidepressant group is one of the psychopharmaceutical management in the earliest cases of enuresis. At least 58 clinical studies have shown that imipramine and other tricyclic antidepressants are effective in reducing the frequency of enuresis to one day per week compared to placebo. ${ }^{3}$ Behavioral therapy is the first choice in enuresis management. This type of therapy ranges from simple behavioral intervention such as fluid restrictions, lifting, scheduled waking, alarms, and reward / reward systems to complex types such as dry-bed training and full spectrum home training. Evidence regarding the effectiveness of these types of therapy is inconclusive due to the limitations of the research conducted. ${ }^{4}$

\section{CASE}

A boy, aged 7 years, was diagnosed with ADHD with symptoms such as inability to concentrate, active movement, talk a lot, unable to wait his turn, unable to delay desires, easy fighting and behaving and speaking harshly. There is a permissive and inconsistent parenting style. Parents are more 
likely to follow the patient's wishes because they are unable to control the patient's emotions and behavior. The Abbreviated Conners Score rating scale assessed by the mother at the start of treatment was 21. The IQ test score was 71 and the Strength and Difficulty Questionnaire (SDQ) score was 35.

Patients have a tendency to perceive slowly. Patients must be accompanied and explained repeatedly while studying. When accompanied by learning, patients often hesitate and have difficulty answering questions. He often reads questions in a hurry and finds it difficult to focus on instructions. In addition, the patient behaves actively and aggressively. His hyperactive condition made the patient get into an argument. Patients are often seen as annoying their friends and triggering fights. This condition makes the patient shunned by friends and often gets reprimands from teachers at school.

When parents find out that a patient's IQ test results are borderline, they become very sad and guilty towards the patient. They become more understanding and understand that patients are idiots. The condition of the patient's intelligence makes the parents more indulgent and takes over all the tasks that the patient should be able to do independently.

Patients still wet the bed at night at least 3-4 times a week. The patient had not previously been trained in toilet training. The patient has just been using baby diapers for the past year (age 6 years).

Patients receive $2 \times 5 \mathrm{mg}$ of methylphenidate treatment, psychoeducation of parents to implement toilet training and behavior therapy for patients, and apply reward and punishment with the principle of token economy. Within 4 months of therapy there was an improvement in the patient's condition. The Abbreviated Conner's Rating Scale score is 1, SDQ score is 11 and Abberant Behavior Checklist Inventory (ABC-i) score is 4.IQ test after 3 months of therapy obtained Full Scale IQ 86 (WISC Scale), Verbal IQ 84, IQ Performance 94.

\section{DISCUSS AND CONCLUSION}

Parenting is an important factor in the development process of children and adolescents. Several studies suggest that parenting can affect a child's resilience and vulnerability to behavioral disorders. ${ }^{5}$ One form is the parenting style of parents who fall into the authoritarian category when parents are too controlling or intrusive which can interfere with the development of self-esteem, self-efficacy, and the ability of a child to solve problems and make decisions. ${ }^{6}$ Parenting patterns that are at the other extreme, namely permissive parenting (overindulgence) are also closely associated with narcissism later in life. Parenting in children with special needs can also exacerbate or accommodate the onset of symptoms or other psychiatric disorders. ${ }^{7}$

Parents can apply reward and punishment. By using the token economy principle, the patient is taught that to ask for something he must say it politely and not force his will. The patient will get a star if the patient performs the desired behavior. When he manages to collect the agreed number of stars, he will get the reward desired by the patient and agreed upon by the parents.

The examiner provides parents with psychoeducation about the goals, how to implement, and the importance of following a schedule of toilet training \& behavior therapy by drinking the last time at $7 \mathrm{pm}$ (1 hour before bed). Wake up at 9-10 at night (the time when the patient usually wet the bed) to urinate then can go back to sleep. One free day of bed-wetting gets one star. If the patient can get 3 stars in seven days (3 days free to wet the bed a week), then the patient will be given a toy car. In the case of children with Attention Deficit Hyperactivity Disorder (ADHD) with borderline intelligent quotient (IQ) and enuresis, parenting with a high parental control component without being balanced with the attitude of parents who are responsive to the child's psychological needs can cause exacerbation of psychological symptoms. there is. This is in line with the study conducted by Çöp and Givertz that there is a relationship between parenting styles of parents who use inconsistent and over-controlling punishment with comorbid oppositional defiant disorder (ODD) and externalizing behavior in ADHD. ${ }^{8}$ In another study conducted by Schuiringa and colleagues, children with borderline IQ with comorbid externalizing behavior have parents with more disciplined parenting, less involved with children's needs, and tend to choose methods with punishment compared to parenting of children with borderline IQ without the comorbid externalizing behavior. ${ }^{9}$ In Kessel's research, he also stated that authoritarian parenting at 3 years of age can be a predictor of enuresis in the future. ${ }^{10}$

\section{REFERENCES}

1. Von Gontard, A., \& Equit, M. (2014). Comorbidity of ADHD and incontinence in children. European Child and Adolescent Psychiatry, 24(2), 127-140. https://doi.org/10.1007/s00787-014-0577-0

2. Elia, J., Takeda, T., Deberardinis, R., Burke, J., Accardo, J., Ambrosini, P. J., Blum, N. J., Brown, L. W., Lantieri, F., Berrettini, W., Devoto, M., \& Hakonarson, H. (2009). Nocturnal Enuresis: A Suggestive Endophenotype Marker for a Subgroup of Inattentive AttentionDeficit/Hyperactivity Disorder. Journal of Pediatrics, 155(2),

239-244.e5. https://doi.org/10.1016/j.jpeds.2009.02.031

3. Caldwell, P. H. Y., Deshpande, A. V., \& VonGontard, A. (2013). Management of nocturnal enuresis. BMJ (Online), 347(October), 1-6. https://doi.org/10.1136/bmj.f6259

4. McLeod, J. D., Uemura, R., \& Rohrman, S. (2012). Adolescent Mental Health, Behavior Problems, and Academic Achievement. Journal of Health and Social Behavior, 53(4), 482-497. https://doi.org/10.1177/0022146512462888

5. Martin, Andres, Bloch, Michael H., Volkmar, F. R. (2017). Lewis's Child and Adolescent Psychiatry: A Comprehensive Textbook (5th Ed.). Lippincott Williams \& Wilkins (LWW).

6. Givertz, M., \& Segrin, C. (2014). The Association Between Overinvolved Parenting and Young Adults' Self-Efficacy, Psychological Entitlement, and Family Communication. Communication Research, 41(8), 1111-1136. https://doi.org/10.1177/0093650212456392

7. Teixeira, M. C. T. V., Marino, R. L. de F., \& Carreiro, L. R. R. (2015). Associations between Inadequate Parenting Practices and Behavioral Problems in Children and Adolescents with Attention Deficit Hyperactivity Disorder. TheScientificWorldJournal, 2015, 683062. https://doi.org/10.1155/2015/683062

8. Çöp, E., Kültür, S., \& Dinç, G. (2017). Association between parenting styles and symptoms of attention deficit 
hyperactivity disorder. Turk Psikiyatri Dergisi.

9. Schuiringa, H., van Nieuwenhuijzen, M., Orobio de Castro, B., \& Matthys, W. (2015). Parenting and the parent-child relationship in families of children with mild to borderline intellectual disabilities and externalizing behavior. Research in Developmental Disabilities, 36, 1-12. https://doi.org/10.1016/j.ridd.2014.08.018

10. Kessel, E. M., Allmann, A. E. S., Goldstein, B. L., Finsaas, M., Dougherty, L. R., Bufferd, S. J., Carlson, G. A., \& Klein, D. N. (2017). Predictors and Outcomes of Childhood Primary Enuresis. Journal of the American Academy of Child and Adolescent Psychiatry, 56(3), 250-257. https://doi.org/10.1016/j.jaac.2016.12.007 